\title{
A APARENTE ANTINOMIA ENTRE O DIREITO CONSTITUCIONAL À LIBERDADE RELIGIOSA E A LIBERDADE DE EXPRESSÃO
}

\section{THE APPARENT CONTRADICTION BETWEEN THE CONSTITUTIONAL RIGHT TO FREEDOM OF RELIGION AND FREEDOM OF EXPRESSION}

\author{
Bruno de Assis Pimentel Carvalhoi \\ Daiana Seabra Venancioii
}

\begin{abstract}
Resumo: O objetivo deste trabalho é compreender a vontade do legislador expressa em normas constitucionais que tratam de direitos fundamentais. Dentre estas, destacam-se as liberdades, especificamente a liberdade religiosa e liberdade de expressão, ambas garantias constitucionais de igual grandeza. Encontra-se atualmente um aparente conflito entre essas duas liberdades, quando uma corrente religiosa busca denegrir outra, propiciando, por vezes, que seus adeptos venham a praticar atos de intolerância, fomentados por essas ideias. Destarte, através do princípio de razoabilidade e da dedução lógica, o trabalho busca analisar o conflito.
\end{abstract}

Palavras-chave: Intolerância Religiosa. Liberdade de Expressão. Antinomia.

Abstract: The aim of this paper is to understand the will of the legislator expressed in constitutional norms that deal with fundamental rights. Among these, we highlight the freedoms, specifically the freedom of religion and freedom of expression, both constitutional guarantees of equal magnitude.lt is currently an apparent conflict between these two

i Graduando em Direito pela Faculdade São José. Membro do Núcleo de Pesquisa e Iniciação Científica das Faculdades São José.

ii Professora das disciplinas de Direito Internacional Público e de Direito Internacional Privado da Faculdade São José. Coordenadora do Núcleo de Pesquisa da Faculdade de Direito São José. 
freedoms, when a religious current seeks to damage another religion, causing sometimes the practice acts of intolerance by its supporters, encouraged by these ideas. Thus, through the principle of reasonableness and logical deduction, the study seeks to analyze the conflict.

Keywords: Antinomy. Religious intolerance. Freedom of Expression.

\section{INTRODUÇÃO}

A análise da prática dos direitos à liberdade religiosa e à liberdade de expressão demonstra o aparente conflito entre estas normas constitucionais, uma vez que, por vezes, alguns grupos religiosos utilizam a liberdade de expressão para denegrir outras religiões. Essas manifestações podem ser interpretadas como forma de limitar a liberdade religiosa, o que faz surgir a importância de entender qual o sentido de uma religião comparar a outra a seu maior "adversário", fato facilmente percebido através de expressões sistematicamente utilizadas, como "inimigo" e "opressor".

A aplicação do princípio de razoabilidade, através da dedução lógica, tem como objetivo sanar a aparente antinomia. Segundo Müller (2005), esta é a melhor forma de resolver um conflito de normas constitucionais.

Para Müller (2005), o processo de decisão jurídica consiste em um procedimento de dedução lógica, sendo então a questão da realização do direito, um problema cognitivo. Sendo, portanto a concretização da norma nada mais do que a interpretação do referido dispositivo, não havendo nada além da reelaboração da vontade da norma (MÜLLER, 2005, p.5).

O presente trabalho objetiva descrever algumas formas de interpretar a Constituição, a fim de que estas possam auxiliar a sanar a antinomia objeto daquele. Müller descreve algumas formas de interpretar as normas constitucionais, a fim de tentar entender a vontade do legislador, a interpretação gramatical, sistemática, teleológica e histórica as quais serão analisadas adiante. (MÜLLER, 2005, p. 6). Estas formas serão analisadas mais adiante, ao expor o princípio de razoabilidade e dedução logica, explicitados por Barroso (BARROSO, 2015, p.255).

É possível justificar esta pesquisa considerando o aumento dos casos de intolerância religiosa no Brasil. A título de ilustrar tal argumento, destaca-se aqui reportagem veiculada pela Empresa Brasil de Comunicação - EBC, publicada no dia 5 de agosto de 2018. Esta reportagem aponta que só na cidade do Rio de Janeiro os casos aumentaram $56 \%$ no período 
de janeiro a março de 2018, quando comparados com o mesmo período do ano anterior (GANDRA, 2018).

Buscando analisar a temática proposta, este trabalho será pautado na investigação a respeito da intolerância religiosa. De forma a atingir a maior veracidade possível no processo de conhecimento da problemática a ser estudada, o trabalho examinará com um olhar investigativo situações referentes ao objeto estudado que, no caso desta análise, trata-se do conflito entre a liberdade de expressão e a liberdade religiosa. O estudo visa a abordar o papel do Ministério Público para sanar tal conflito; para isso, faz-se necessário direcionar a abordagem em base da utilização de material teórico, estabelecendo uma linha de investigação pela qual será conduzido o trabalho, para que seja levantado todo o material necessário com o intuito de estabelecer uma avaliação prática do que se propõe o estudo.

Após o levantamento do material teórico, o estudo seguirá distribuído em quatro fases distintas, as quais serão avaliadas separadamente. A primeira buscará o conhecimento teórico referente à contextualização do objeto estudado. A segunda buscará estudar quais os dispositivos legais que asseguram tais direitos. A terceira fase terá por objetivo estudar qual o papel do Ministério Público. A quarta fase terá a responsabilidade de traçar um paralelo entre a segunda e a terceira fases.

Este trabalho visa atuar utilizando o método da pesquisa bibliográfica, a fim de produzir um aprofundamento acerca do tema proposto, desta forma avaliando a veracidade das hipóteses levantadas. Sendo dividido em três capítulos, no primeiro serão abordados aspectos referentes ao direito à liberdade de expressão; no segundo, quanto à liberdade religiosa, e, por fim, o terceiro pontuará a possibilidade de o Ministério Público auxiliar a sanar a aparente antinomia.

\section{A RELEVÂNCIA DA LIBERDADE NA CONSTITUIÇÃO}

A Constituição Federal traz, em seu escopo, diversas normas com fins de assegurar direitos fundamentais ao indivíduo. $O$ constituinte buscou garantir liberdades variadas, que são essenciais para assegurar a dignidade da pessoa humana. Tamanha é a relevância, que o constituinte originário considera a dignidade da pessoa humana como condição de fundamento do Estado Democrático de Direito. 
Diversos tratados e convenções internacionais versam sobre o assunto. Após a Emenda constitucional $n^{\circ} 45$ (EC/45), os tratados que versam sobre direitos humanos, ao serem ratificados pelo Brasil, passaram a ser inseridos no ordenamento jurídico brasileiro com grande relevância. O Recurso Extraordinário 466.339, julgado em 2009, do Supremo Tribunal Federal (STF) passou a reconhecer que os tratados que versam sobre Direitos Humanos, mesmo quando aprovados por maioria simples, possuem status de norma supralegal, ou seja, acima das leis e abaixo da Constituição Federal. O parágrafo $3^{\circ}$, incluído pela $\mathrm{EC} / 45$, reconhece $\mathrm{O}$ status de emenda constitucional desses tratados, quando aprovados pelo Congresso Nacional, pelas duas casas, em dois turnos, com três quintos de seus membros.

$\mathrm{Na}$ esfera internacional, há no continente americano a Convenção Americana de Direitos Humanos, mais conhecida como Pacto de São José da Costa Rica, que institui o Sistema Interamericano de Proteção aos Direitos Humanos. Este complementa a proteção aos direitos humanos dos estados membros. O Pacto de São José da Costa Rica institui a Corte Interamericana de Direitos Humanos (CIDH), que possui o papel consultivo e contencioso, este último apenas para os estados que são parte do Pacto e aceitaram a jurisdição da Corte.

O tema da dignidade de pessoa humana, na Constituição Brasileira possui caráter de conditio sinequa non, para a existência do Estado Democrático de Direito. Por este motivo, existem diversos direitos fundamentais assegurados no texto constitucional e, conforme dispõe o art. $5^{\circ}, \S 2^{\circ}$, tais direitos não excluem outros previstos em convenções e tratados internacionais. Uma eventual violação a estes direitos fundamentais podem levar o Brasil a ser acionado na Corte Interamericana de Direitos Humanos.

\subsection{Liberdade de expressão}

A liberdade de expressão é inerente ao indivíduo. Na Antiguidade clássica já era possível encontrar o exercício deste direito. Na democracia de Atenas, em 507 a.C. quando Clístenes assumiu o poder, ele estendeu os direitos políticos a todos os cidadãos atenienses, ou seja, homens livres, maiores de idade e nascidos em Atenas. Com isso, todo cidadão ateniense passou a ter o direito de fazer uso da palavra na Bulé. Esta consiste em uma assembleia formada pelo povo que, entre outras coisas, era consultada em assuntos importantes (KITTO, 1970, p.108). No ordenamento jurídico brasileiro, encontramos, na Carta Magna, a garantia deste direito 
à liberdade de expressão como fundamental e indispensável ao Estado Democrático de Direito.

O direito de manifestar seu pensamento está expresso no artigo $5^{\circ}$, inciso IV, da Constituição: "é livre a manifestação do pensamento sendo vedado o anonimato" juntamente com o inciso XIV deste mesmo artigo, no qual "é assegurado a todos o acesso à informação e resguardado o sigilo da fonte, quando necessário ao exercício profissional". Une-se ao artigo $5^{\circ} \mathrm{o}$ artigo $220 \mathrm{com}$ o mesmo propósito de assegurar o direito à liberdade de expressão, em seu caput, afirma que "a manifestação do pensamento, a criação, a expressão e a informação, sob qualquer forma, processo ou veículo não sofrerão qualquer restrição, observado o disposto nesta Constituição", bem como o $\S 1^{\circ}$ deste artigo: "nenhuma lei conterá dispositivo que possa constituir embaraço à plena liberdade de informação jornalística em qualquer veículo de comunicação social, observado o disposto no artigo $5^{\circ}$, IV , V , X, XIII e XIV." Por fim, o $\S 2^{\circ}$ estabelece que "é vedada toda e qualquer censura de natureza política, ideológica e artística." São dispositivos constitucionais que buscam garantir o direito à liberdade de expressão.

Tamanha é a relevância deste direito, que encontra amparo na legislação internacional para sua garantia. Neste sentido, serão analisadas, a seguir, algumas declarações e tratados internacionais, através dos quais o Brasil se comprometeu com a preservação da liberdade de expressão.

A Declaração Universal dos Direitos Humanos consiste em um documento que proclama os direitos humanos básicos, e estabelece no artigo XIX que "todo homem tem direito à liberdade de opinião e de expressão; este direito inclui a liberdade de, sem interferências, ter opinião e de procurar, receber e transmitir informações e ideias por quaisquer meios, independentemente de fronteiras" (ONU, 2009, p.p. 10-11).

A Declaração Internacional de Chapultepec, uma carta de princípios que se tornou decisiva para a defesa da liberdade de expressão na América Latina, foi assinada pelo Brasil em 9 de agosto de 1996. Busca defender e valorizar a liberdade de imprensa e de expressão e, em seus princípios, estabelece que:

"I. Não há pessoas nem sociedades livres sem a liberdade de expressão e de imprensa. O exercício desta não é uma concessão das autoridades; é um direito inalienável do povo.

II. Toda pessoa tem direito de buscar e receber informação, expressar opiniões e divulgá-las livremente (ONU, 1994)." 
O Pacto Internacional de Direitos Civis e Políticos (PIDCP) foi promulgado no Brasil através do Decreto no 592, de 6 de julho de 1992. Possui um protocolo facultativo, ratificado pelo Brasil em 2009, que busca assegurar o melhor resultado dos propósitos do Pacto, criando um mecanismo de petições individuais. Buscou-se que este fosse um Pacto que reunisse todos os direitos e garantias individuais, como exemplificado no artigo abaixo:

\begin{abstract}
"Toda pessoa terá o direito à liberdade de expressão; esse direito incluirá a liberdade de procurar, receber e difundir informações e ideias de qualquer natureza, independente de considerações de fronteiras, verbalmente ou por escrito, de forma impressa ou artística, ou por qualquer meio de sua escolha (BRASIL, 1992)."
\end{abstract}

O Pacto de São José da Costa Rica é um dos documentos mais importantes no campo dos direitos humanos no continente americano. Este é o instrumento fundamental do Sistema Interamericano de Proteção aos Direitos Humanos (SIPDH) e institui a Corte Interamericana de Direitos Humanos. Esta corte é um órgão jurisdicional do SIPDH que tem a função de resolver casos de violação aos direitos humanos perpetrados pelos estados partes, como se pode observar no seguinte trecho:

"Toda pessoa tem o direito à liberdade de pensamento e de expressão. Esse direito inclui a liberdade de procurar, receber e difundir informações e ideias de qualquer natureza, sem considerações de fronteiras, verbalmente ou por escrito, ou em forma impressa ou artística, ou por qualquer meio de sua escolha (CONVENÇÃO..., 1969)."

Os tratados acima, ao mesmo tempo em que buscam defender e assegurar o direito à liberdade de expressão, não o definem como um direito absoluto. Assim sendo, este deve ser entendido de forma a assegurar também outros direitos fundamentais de igual grandeza. A liberdade de expressão deve ser exercida de forma responsável. Na verdade, todas as liberdades constitucionais devem ser exercidas com responsabilidade, de modo que o direito de um indivíduo não interfira no direito do outro.

O direito à liberdade de expressão é um dos direitos fundamentais mais importantes, pois deriva do clamor individual do homem de todos os tempos. O filosofo austríaco, economista e ganhador do Prêmio Nobel de Economia de 1974, Friedrich August Von Hayek, no capítulo cinco de 
seu livro "Os fundamentos da liberdade", explica que a relação entre o indivíduo, a sociedade e a liberdade deve dar-se de modo responsável, consciente de que o indivíduo arca com as consequências de suas ações, como se pode observar neste trecho:

"Liberdade não apenas significa que o indivíduo tem a oportunidade e, ao mesmo tempo, a responsabilidade de escolher; também significa que deve arcar com as consequências de suas ações, pelas quais será louvado ou criticado. Liberdade e responsabilidade são inseparáveis (HAYER, 1983, p.90)."

Liberdade e responsabilidades são inseparáveis, diz Hayek; desta forma todas as liberdades garantidas na Constituição devem ser exercidas com responsabilidade. O indivíduo, ao exercer sua liberdade, deve ter consciência de que irá responder por suas atitudes. Assim, na garantia da liberdade religiosa, o indivíduo precisa ter claro que o limite do seu direito é o direito do outro.

\subsection{Liberdade religiosa}

No rol das liberdades asseguradas dentre os direitos fundamentais, igual magnitude possui a garantia da liberdade religiosa. Ao falar de liberdade religiosa, inclui-se a liberdade de crença e a liberdade do exercício de seu devido culto. O ordenamento jurídico brasileiro assevera que o Estado não pode interferir na organização da entidade religiosa, nem em sua economia (MENDES; COELHO; BRANCO, 2010, p.511).

Em igual sentido destaca-se que esta liberdade deve assegurar ao indivíduo a liberdade de não crer, de não exercer nenhuma crença, ou seja, se o Texto Magno garante que o indivíduo pode escolher livremente sua crença, neste mesmo sentido deve permitir a este o direito de não possuir crença - ou seja, o ateísmo - sem por isso sofrer qualquer tipo de discriminação ou censura.

O artigo 19, I, da Constituição garante que o Brasil seja um país laico, no sentido de não confessional. O Estado Brasileiro não pode possuir uma religião oficial, para assim não constranger o exercício de nenhuma prática religiosa. Desta forma, não pode o Estado impedir ou dificultar nenhum tipo de manifestação religiosa, garantindo a cada indivíduo o direito de escolher e praticar a sua religião. 
Por religião entende-se um conjunto de rituais e crenças em um ser transcendental (GARVEY; SCHAUER, 1996, p.595). O Brasil é um Estado laico, porém não é um Estado inimigo da religião, como é possível observar no preâmbulo da Constituição:

"Nós representantes do povo brasileiro, reunidos em Assembleia Nacional Constituinte para instituir um Estado Democrático, destinado a assegurar o exercício dos direitos sociais e individuais, a liberdade à segurança, o bem -estar, o desenvolvimento, a igualdade e a justiça como valores supremos de uma sociedade fraterna, pluralista e sem preconceitos, fundada na harmonia social e comprometida, na ordem interna e internacional, com a solução pacífica das controvérsias promulgamos, sob a proteção de Deus, a seguinte CONSTITUIÇÃO DA REPUBLICA FEDERATIVA DO BRASIL (BRASIL, 1988)."

O constituinte promulga a Constituição "sob a proteção de Deus"; entretanto, como este não professa nenhum tipo de credo em concreto, pode-se entender que, ao evocar a proteção de Deus, este esteja se referindo à ideia abstrata de um ser transcendente, não à divindade de alguma religião específica. Neste sentido, compreende-se que seja admitido o ensino religioso confessional nas escolas para os alunos interessados, como decidiu o STF na Ação Direta de Inconstitucionalidade 4.439, julgada em 27 de setembro de 2017.

$\mathrm{Na} A \mathrm{DI}$, a supra citada Suprema Corte Brasileira entende que a menção a Deus no preâmbulo da Constituição não fere a laicidade do Estado, tendo em vista que o preâmbulo não possui força normativa, não cria direitos nem obrigações.

Estado laico não significa um Estado inimigo da fé, inclusive são possíveis alguns tipos de parcerias entre o Estado e as religiões, que visem atender o interesse público, como, por exemplo, estender os efeitos do casamento civil aos casamentos religiosos.

As religiões, em geral, buscam promover o bem integral de seus adeptos e, por consequência, o bem coletivo. Esta busca pelo bem-estar social de cada indivíduo se compatibiliza com uma das finalidades do Estado Democrático, expresso no preâmbulo da Constituição.

A obra escrita por Gilmar Mendes, Inocêncio Mártires Coelho e Gustavo Gonet Branco (2010, p. 513) afirma que para o sistema jurídico a religião consiste em um bem em si, como um valor a ser preservado e fo- 
mentado. Além disso, o Estado, ao reconhecer a liberdade religiosa como um direito fundamental, deve promover e estimular esta liberdade. Neste aspecto, concorre o fato de, por inúmeras vezes, a formação moral apregoada pelas religiões contribuir para a formação de caráter do indivíduo.

Neste mesmo aspecto, os feriados religiosos são entendidos no sentido de reacender na memória as raízes culturais e históricas do povo (HABERLE, 2001, p.284). Considerando que liberdade religiosa consiste em assegurar o direito de cada um de professar a sua fé, não é cabível arguir a liberdade religiosa a fim de impedir a demonstração de fé de outrem.

Pode uma religião recomendar que seus adeptos não frequentem outras, alegando que seus dogmas são incompatíveis. Neste sentido, o Estado não pode interferir, uma vez que está impedido de intervir no funcionamento de qualquer religião, desde que assim não o imponha algum valor constitucional concorrente (HABERLE, 2001, p.285).

Quando uma religião, ao proibir que seus adeptos frequentem outra, utiliza um discurso de ódio, fomentando, assim, em seus adeptos a ideia de que outras religiões não são boas, não visa ao bem-estar social. E quando estas ideias, ao serem muito difundidas, acompanhadas de uma tradição de preconceito e discriminação contra as classes e etnias majoritárias desta religião, geram discriminação e preconceito, pode o Estado intervir?

É dever do Estado assegurar e promover a liberdade religiosa para todos, assim sendo, quando uma religião utiliza um discurso de ódio para com outra, o que acarreta a limitação e até a violação do seu direito à liberdade religiosa, deve o Estado impedir.

\section{A ANTINOMIA ENTRE LIBERDADE DE EXPRESSÃO E LIBERDADE RELIGIOSA}

A Constituição Federal de 1988 define os direitos fundamentais e os proclama. Estes direitos fundamentais designam no nível do direito positivo, as prerrogativas que visam garantir uma convivência digna, livre e igual, segundo José Afonso da Silva (SILVA, 2015, p. 57). As normas constitucionais gozam de mesmo status hierárquico, não havendo distinção entre elas.

O constituinte assegura com grande relevância o direito à liberdade religiosa, sendo assegurado o livre exercício dos cultos religiosos. De igual forma assegurou com igual importância o direito à liberdade de expressão. 
Ambas as garantias são imprescindíveis a uma democracia. Entretanto, há momentos em que um direito pode conflitar com o outro. Quando, em nome da liberdade de expressão, uma pessoa, ou um líder religioso, afirma que outra religião é "coisa do demônio" ele pode estar ferindo o direito à liberdade religiosa?

A Igreja Católica Apostólica Romana, em um dos livros que são base de sua doutrina, o Catecismo da Igreja Católica, descreve sua visão acerca do espiritismo:

"Todas as formas de adivinhação hão de ser rejeitadas: recurso a Satanás ou aos demônios, evocação dos mortos ou outras práticas que erroneamente se supõe descobrir o futuro. A consulta aos horóscopos, à astrologia, a quiromancia, a interpretação de presságios e da sorte, os fenômenos de visão, o recurso a médiuns esconde uma vontade de poder sobre o tempo, a história e, finalmente, sobre os homens, ao mesmo tempo em que um desejo de ganhar para si os poderes ocultos. Essas práticas contradizem a honra e o respeito que, unidos ao amoroso temor, devemos exclusivamente a Deus (CATECISMO..., 2000, p. 2116)."

"Todas as práticas de magia ou de feitiçaria com as quais a pessoa pretende domesticar os poderes ocultos, para colocá-los a seu serviço e obter um poder sobrenatural sobre o próximo - mesmo que seja para proporcionar a este a saúde -, são gravemente contrárias à virtude da religião. Essas práticas são ainda mais condenáveis quando acompanhadas de uma intenção de prejudicar a outrem, ou quando recorrem à intervenção dos demônios. O uso de amuletos também é repreensível. O espiritismo implica frequentemente práticas de adivinhação ou de magia. Por isso a Igreja adverte os fiéis a evitá-lo. O recurso aos assim chamados remédios tradicionais não legitima nem a invocação dos poderes maléficos nem a exploração da credulidade alheia (CATECISMO..., 2000, p. 2117)."

Em virtude da descrição utilizada, entendemos que esteja se referindo ao espiritismo em sentido amplo, o que abrange o chamado "Kardecismo" e as religiões de matrizes africanas. Tendo em vista que a doutrina católica e outras religiões de origem cristã consideram o espiritismo e as religiões de matriz africana como ligadas ao "demônio", faz-se necessário buscar brevemente entender o que seria o "demônio" para o cristianismo, segundo a Bíblia. 
Neste trabalho utilizam-se os termos "demônio, satanás, diabo" como sinônimos. O texto da Bíblia, livro sagrado para os cristãos, fala que: "até mesmo aos espíritos impuros dá ordens, e eles obedecem!" (BÍBLIA..., 2003, MC 1, 27b); "chamou os doze discípulos e deu-lhes autoridade de expulsar os espíritos impuros" (BÍBLIA..., 2003, MT 10, 1ª); "Sede sóbrios e vigilantes! Eis que o vosso adversário, o diabo, os rodeia como um leão a rugir procurando a quem devorar" (BÍBLIA..., 2003, 1Pe, 5,8).

Segundo os trechos supracitados, a figura do "demônio" é associada como algo "impuro, adversário". Desta forma, é possível afirmar que, ao comparar uma religião ao demônio, subtende-se que esta religião é impura, é adversária aos valores cristãos. Considerando que, segundo os cristãos, o demônio é aquilo que deve ser combatido, que deve ser erradicado da sociedade, é possível deduzir que o cristianismo prega que as religiões chamadas de espíritas devem ser combatidas? É importante frisar que não é a proposta deste trabalho julgar as doutrinas das religiões, mas sim, analisar as atitudes de alguns de seus praticantes. A partir disso, busca-se compreender o surgimento de uma aparente antinomia entre a liberdade de manifestação do pensamento e a liberdade de crença, bem como o papel do Ministério Público no enfrentamento deste problema.

De que modo o Estado consegue assegurar o direito à liberdade de expressão sem que esta seja conflitante com a liberdade religiosa? Interpretando a Constituição através do princípio da razoabilidade ou da proporcionalidade e da dedução lógica.

\subsection{0 princípio da razoabilidade}

Segundo Barroso, este princípio "é o produto da conjugação de ideias vindas de dois sistemas diversos" (BARROSO, 2015, p. 255): o estadunidense, no devido processo legal; e do alemão, no princípio da proporcionalidade. Funciona com um critério de aferição da constitucionalidade de algumas leis, possui em si valores como racionalidade, justiça, medida adequada, senso comum, rejeição aos atos arbitrários.

Pode-se dizer que o princípio de razoabilidade consiste em um mecanismo de controle da discricionariedade legislativa. Entende-se por razoável tudo aquilo que é conforme a razão, o que não é arbitrário. Consiste em uma adequação entre o meio empregado e o fim pretendido. 
Deve-se ter em vista também a necessidade ou a aplicabilidade da medida, devendo-se verificar a existência de meio menos gravoso para a obtenção do mesmo fim. Por fim, deve-se ainda considerar a ideia de proporcionalidade em sentido estrito, devendo-se sempre ponderar entre o ônus imposto e o benefício obtido, a fim de aferir se a medida é válida. (BARROSO, 2015, p. 267).

Barroso afirma que este princípio é habitualmente utilizado para sanar aparentes antinomias entre dispositivos constitucionais, de modo especial as que tangem aos direitos humanos (BARROSO, 2015, p.268). Segue ele afirmando que este princípio é utilizado de modo estrito quando a matéria em disputa envolve temas como, entre outros, a liberdade de expressão e a liberdade religiosa.

\subsection{A dedução lógica}

Muller, citando o Tribunal Constitucional Federal da República da Alemanha, diz que a norma deve ser interpretada de modo que esta possa ser aplicada na prática. Tal interpretação deve se dar "a partir do nexo sistemático da norma a partir de sua codificação ou do ordenamento jurídico global e, por fim, a partir do sentido e da finalidade, a partir da ratio". (MÜLLER, 2005, p. 6).

Deste modo entende-se que a forma mais própria para a interpretação da norma constitucional se dá através do silogismo lógico, devendo-se identificar o conteúdo da norma. A interpretação deve ser feita ultrapassando a vontade objetiva da norma e buscando a vontade subjetiva do constituinte (MÜLLER, 2005, p. 6).

Assim, deve-se compreender o teor da norma como premissa maior. Em seguida, são submetidas às circunstâncias da vida como premissa menor e a decisão jurídica é obtida através de dedução lógica. Desta forma, o problema jurídico de interpretação de normas constitucionais é entendido como uma questão cognitiva. Servem também, de subsídio à interpretação da norma constitucional, quatro outros métodos:

"Ao objetivo da interpretação de identificar a vontade do legislador objetivada na lei servem as interpretações a partir do teor literal da norma (interpretação gramatical), a partir do seu nexo (interpretação sistemática), partir da sua finalidade (interpretação teleológica) e a partir dos materiais legais e da história genética (interpretação histórica). (MÜLLER, 2005, p. 7)." 
Estes métodos de interpretação devem ser usados em conjunto a fim de se compreender a vontade do legislador, presente na norma constitucional. Esta vontade do legislador deve sempre ser levada em consideração com cautela, na medida em que ela pode ser identificada expressa na norma escrita. Não se deve, todavia, igualar a vontade subjetiva do legislador à sua vontade objetiva, expressa na norma.

\subsection{A aplicação dos princípios à dicotomia entre liberdade de expressão e liberdade religiosa}

O caso em voga trata-se de um aparente conflito entre direitos fundamentais previstos na Constituição Brasileira e balizados por convenções e tratados internacionais dos quais o Brasil é signatário. De um lado, o direito inalienável à liberdade de expressão; de outro, de igual envergadura, o direito à liberdade religiosa.

Por vezes, a título de fazer uso do direito à liberdade de expressão, denigre-se e difama-se outras religiões, em especial aquelas de matriz africana, simplesmente por não concordarem com suas doutrinas. A difusão desse pensamento faz brotar um sentimento de ódio contra essas religiões e seus adeptos, fazendo com que sejam vítimas de discriminação e intolerância religiosa.

Ao tratar aqui de intolerância religiosa, entende-se em seus diversos aspectos que intolerância religiosa vai desde a prática de agressão moral, verbal e até física contra outrem, unicamente em virtude da religião. Incluem-se aqui também os atos velados de discriminação religiosa, quando instituições religiosas ou seus adeptos são privados de seus direitos que são assegurados a todos os indivíduos, unicamente em virtude da religião professada.

A fim de solucionar esta antinomia aparente, deve-se utilizar a dedução lógica e o princípio de razoabilidade da interpretação da norma constitucional. O bem maior a ser tutelado pelo Estado é a vida, a dignidade da pessoa humana. Nestes termos, as normas têm que se coadunar de modo que a coisa mais importante a ser garantida deva ser a vida e a dignidade da pessoa humana.

Destarte, não pode haver uma liberdade de expressão que fomente ideias que coloquem em risco a vida de outrem. Todas as pessoas têm o direito de se manifestar em favor ou contra determinada religião; entretanto, esta manifestação não pode, de forma alguma, direta ou indiretamente, colocar em risco a integridade ou a dignidade de outrem. 
Como foi citado acima, Hayer pontua que liberdade e responsabilidade são indissociáveis. Então, aquele que se propõe a tecer comentários ou críticas contra outrem deve usar de bom senso e parcimônia, a fim de que seu direito não interfira no direito do outro.

O direito à liberdade de expressão não é absoluto, cessa onde começa outro direito, neste caso, o direito à liberdade religiosa. Não podendo harmonizar os dois direitos, deverá prevalecer um sobre o outro, tendo como norte a defesa da vida e da dignidade da pessoa humana.

\section{MINISTÉRIO PÚBLICO COMO POSSIVEL AUXILIAR PARA SANAR AS ANTINOMIAS}

Isso posto, será tecida breve análise quanto às atribuições do Ministério Público na resolução de conflito de normas de interesse difuso.

É relevante a análise do papel do Ministério Público, enquanto guardião da ordem jurídica, na resolução deste conflito de normas. Haja vista que, com a Lei da Ação Civil Pública (Lei no 7.347/85), o Ministério Público ganha destaque como agente de promoção dos interesses difusos, ou seja, tem o Ministério Público o dever de defender o interesse coletivo. Atualmente, "ganhou o desenho de instituição voltada à defesa dos interesses mais elevados da convivência social e política, não apenas perante o Judiciário, mas também na ordem administrativa" (MENDES; COELHO; BRANCO, 2010, p.1.141). Portanto, entende-se que é papel do Ministério Público buscar meios para assegurar o direito à liberdade religiosa, e, ao mesmo tempo assegurar o direito à liberdade de expressão.

A Constituição reconhece o Ministério Público como instituição de relevante importância, como uma das funções essenciais à justiça. Possuindo este, após a Constituição de 1988, poderes alargados, consiste em uma instituição com deveres de defesa dos interesses mais elevados da convivência social. O artigo 127 da Constituição o define como uma "instituição permanente, essencial à função jurisdicional do Estado, incumbindo-Ihe a defesa da ordem jurídica, do regime democrático e dos interesses sociais individuais indisponíveis".

O § $1^{\circ}$ do artigo 127 elenca como princípios desta instituição "a unidade, a indivisibilidade e a independência funcional". Por unidade entende-se que promotores e procuradores integrem um único órgão com 
um único chefe. A unidade permite que estes possam ser substituídos uns pelos outros, sem assim comprometer o trabalho da instituição. A independência funcional assegura que, no que tange à sua atividade funcional, cada membro da instituição esteja vinculado unicamente à sua consciência e à observância fiel da legislação vigente, sem estar subordinado a interesses de terceiros.

As garantias constitucionais de vitaliciedade, inamovibilidade e de irredutibilidade de salários afastam dos membros do Ministério Público quaisquer coisas que possam inibir o livre exercício de suas funções. Essas garantias, ao mesmo tempo em que protegem os membros desta instituição, visam assegurar a autoridade que lhes é conferida pelo constituinte.

Dentre as competências do Ministério Público, destaca-se aqui o dever de zelar pelos interesses difusos e coletivos, conforme previsto no inciso II do artigo 129 da Constituição Federal. Entende-se que os interesses difusos são aqueles que ultrapassam a pessoa de um único indivíduo e devem atingir a coletividade, ou seja, são metaindividuais. É, portanto, dever do Ministério Público assegurar a garantia dos direitos fundamentais previstos na Constituição, por serem estes direitos de todos os indivíduos.

Desta forma, é atribuição do Ministério Público buscar formas para garantir que os indivíduos possam exercer sua liberdade de expressão e sua liberdade religiosa. Considerando que, por vezes, como se observou anteriormente, ocorrem conflitos entre estas normas, cabe ao Ministério Público utilizar-se de todas as ferramentas que lhe forem acessíveis a fim de buscar sanar esta aparente antinomia e assegurar que ambas as garantias sejam exercidas em harmonia.

\section{CONCLUSÃO}

O Texto Magno busca assegurar direitos fundamentais ao indivíduo. Entre estes direitos, estão as liberdades, que devem sempre ser exercidas com responsabilidade. Dentre estas liberdades está a de expressão, que consiste no direito de manifestar seu pensamento. Esse direito constitucional está fundamentado também nas convenções e tratados internacionais ratificados pelo Brasil.

Igual importância possui a garantia à liberdade religiosa. Esta assegura ao indivíduo o direito de escolher qual credo deseja professar e Ihe permite exercer a prática de sua crença sem qualquer intervenção do Estado. 
Por vezes, o exercício da liberdade de expressão entra em confronto com a liberdade religiosa, quando, por exemplo, utiliza-se da liberdade de expressão para denegrir alguma religião. Por vezes, estas manifestações acabam por disseminar uma ideia de ódio a religiões diferentes. Este discurso de ódio muitas vezes se converte em atos concretos de intolerância.

Este aparente conflito de normas encontra solução ao ser interpretado através da dedução lógica e do princípio de razoabilidade. Deve-se interpretar estes dispositivos constitucionais de modo que o bem mais importante seja a garantia da vida e da dignidade da pessoa humana. Desta forma, pode-se exercer a liberdade de expressão com responsabilidade, de modo que a manifestação do pensamento de um indivíduo não ofereça risco à vida ou à dignidade de outrem.

\section{REFERÊNCIAS}

BARROSO, Luís Roberto. Curso de Direito Constitucional contemporâneo. 5. ed. São Paulo: Saraiva, 2015.

BÍBLIA de Jerusalém. São Paulo: Paulus, 2003.

BRASIL. Constituição (1988). Constituição da República Federativa do Brasil. Brasília: Senado, 1988.

BRASIL. Decreto no 592, de 6 de julho de 1992. Atos Internacionais. Pacto Internacional sobre Direitos Civis e Políticos. Promulgação. Disponível em: <http://www.planalto.gov.br/ccivil_03/decreto/1990-1994/d0592. htm >. Acessado em: 27 jan. 2018.

CATECISMO da Igreja Católica. São Paulo: Loyola, 2000.

CONVENÇÃO Americana sobre os Direitos Humanos.1969. Pacto de São José da Costa Rica. Disponível em: <https://www.cidh.oas.org/basicos/ portugues/c.convencao_americana.htm>. Acesso em: 07 nov. 2018.

GANDRA, Alana. Casos de intolerância religiosa sobem $56 \%$ no estado do Rio. Empresa Brasil de Comunicação, Rio de Janeiro, 8 maio 2018. Agência Brasil, Direitos Humanos. Disponível em: <http://agenciabrasil. 
ebc.com.br/direitos-humanos/noticia/2018-05/casos-de-intolerancia-religiosa-sobem-56-no-estado-do-rio>. Acesso em: 7 nov. 2018.

GARVEY, John H.; SCHAUER, Frederick. The first amendment: a reader. St. Paul: West Publishing Co., 1996.

HABERLE, Peter. El Estado constitucional. México: UNAM, 2001.

HAYER, Friedrich August. Os Fundamentos da liberdade. [S.I.]: Editora visão, 1983.

KITTO, H. D. F. Os gregos. Coimbra: Armério amado, editor, sucessor, 1970.

MENDES, Gilmar Ferreira; COELHO, Inocêncio Mártires; BRANCO, Gustavo Gonet. Curso de direito constitucional. 5. ed. rev. e atual. São Paulo: Saraiva, 2010.

MÜLLER, Friedrich. Métodos de trabalho do direito constitucional. 3. ed. Rio de Janeiro: Renovar, 2005.

ONU. Declaração Internacional de Chapultepec. 1994. Disponível em: <http://www.direitoshumanos.usp.br/index.php/Documentos-não-Inseridos-nas-Deliberações-da-ONU/declaracao-de-chapultepec-1994.html>. Acesso em: 07 nov. 2018.

Declaração Universal dos Direitos Humanos. [S.I.: s.n.], 2009. Disponível em: <https://nacoesunidas.org/wp-content/uploads/2018/10/ DUDH.pdf >. Acesso em: 08 nov. 2018.

SILVA, José Afonso da. Curso de Direito Constitucional Positivo. 25. ed. São Paulo: Malheiros, 2005. 